\title{
LA MORAL INDIVIDUAL Y LA MORAL DE LAS INSTITUCIONES*
}

\author{
Thomas M. Scanlon
}

Harvard University

\begin{abstract}
RESUMEN: Este trabajo desarrolla la relación entre la filosofía moral y la filosofía política. Se sostiene que, de alguna manera, la filosofía política es parte de la filosofía moral, en el sentido que la primera se preocupa del contenido de los estándares morales que rigen las relaciones de los individuos con las instituciones. Éste sería el objeto de la "moral de las instituciones", mientras que la así llamada "moral individual" se ocuparía de los estándares que se aplican a los individuos. Sobre la base de una concepción de la moral indi-
\end{abstract}

Thomas M. Scanlon. Profesor Alford de religión natural, filosofía moral y política civil en el Departamento de Filosofía de la Universidad Harvard. Primero se interesó en lógica-matemática (fue discípulo de Paul Benacerraf), pero pronto se dedicó a la filosofía moral y filosofía política, la que ha desarrollado principalmente en Harvard, donde obtuvo su Ph.D. en filosofía en 1968. Ha desarrollado una versión del contractualismo similar a las de Rawls, Kant y Rousseau, pero como teoría de la obligación moral. Esta teoría se encuentra expuesta en su What We Owe to Each Other (1998). Es autor además de varios artículos sobre libertad de expresión, derechos civiles y el concepto de bienestar, algunos de los cuales están recogidos en su libro The Difficulty of Tolerance (2003). Otras monografías incluyen Moral Dimensions: Permissibility, Meaning, Blame (2008) y recientemente su Being Realistic about Reasons (2014) que recopila sus charlas John Locke dictadas en la Universidad de Oxford en 2009. Estudios Públicos reprodujo antes su artículo seminal "Contractualismo y utilitarismo", escrito en 1982 (101, verano 2006). Email: scanlon@fas.harvard.edu.

* Este trabajo corresponde a un texto inédito presentado como ponencia por su autor en el Centro de Ética Edmond J. Safra de la Universidad Harvard, en 2010. Cuenta con la debida autorización del autor para su publicación en castellano. Traducción de Javier Gallego Saade (CEP). 
vidual vinculada al contractualismo, y un desarrollo de la moral de las instituciones que sigue de cerca la teoría de la justicia de John Rawls, el trabajo se pregunta por el fundamento de la obligación de cumplimiento de estándares definidos por instituciones y dirigidos a los individuos. Se pone al final especial atención a la dificultad de fundamentar dicha obligación en el caso de instituciones injustas.

PALABRAs ClAVE: Filosofía moral, filosofía política, instituciones, teoría de la justicia, John Rawls, deberes de cumplimiento.

RECIBIDO: abril 2014; ACEPTADO: mayo 2014.

\title{
INDIVIDUAL MORALITY AND THE MORALITY OF INSTITUTIONS
}

\begin{abstract}
This paper discusses the relationship between moral philosophy and political philosophy. It holds that political philosophy in some way is part of moral philosophy as the former deals with the content of moral standards governing the relations between individuals and institutions. That would be the purpose of the "morality of institutions," while the so-called "individual morality" would inform the standards applicable to individuals. On the basis of a conception of individual morality as it relates to contractualism and a discussion of the morality of institutions that closely follows John Rawls' theory of justice, the paper addresses the question of the foundations of the obligation to comply with institution-defined standards that are directed towards individuals. At the end, it focuses in particular on the difficulty of rationalizing that obligation in the case of unjust institutions.
\end{abstract}

Keywords: Moral philosophy, political philosophy, institutions, theory of justice, John Rawls, duty of compliance.

RECEIVED: April 2014; ACCEPTED: May 2014.

\section{INTRODUCCIÓN}

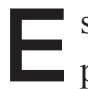
ste trabajo desarrolla la relación entre la filosofía moral y la filosofía política, o más bien la relación entre los objetos de estudio de ambas disciplinas. ¿Es la filosofía política simplemente un subgénero de la filosofía moral? Me parece que en un aspecto importante lo es, pero hay, no obstante, algo reconocible como original. Según lo adelanta el título de mi trabajo, en lo que sigue entenderé que la primera y básica distinción surge al constatar que la filosofía política se preocupa por las instituciones de un modo que la hace diversa de la filosofía moral, o del resto de la filosofía moral, lo que aquí denominaré "moral individual". 
Con el concepto "moral individual" hago referencia a los estándares morales que se aplican a los individuos. En lo primordial se trata de estándares determinantes de la permisibilidad, impermisibilidad, y reprochabilidad de acciones individuales, aunque también pueden incluir conclusiones sobre aquellos valores — referidos a la mejor forma de vivir- que son comúnmente denominados "valores morales". Muchos estándares morales se aplican a nosotros sin importar si otros los cumplen de modo general. Por ejemplo, la prohibición de uso de fuerza letal tiene excepciones: está permitido el uso de fuerza letal cuando somos atacados y se hace necesario conservar la vida. Pero esta prohibición general (y sus excepciones) es válida independientemente del hecho de su observancia. Seguirá siendo incorrecto atacar a una persona que no representa una amenaza para nosotros incluso si la mayoría deja de observar este comportamiento. No obstante esto, existen otras conclusiones sobre la permisibilidad de las acciones de individuos que sí dependen de los principios que otros, de hecho, siguen.

Supongamos, por ejemplo, que el uso generalizado de productos que contienen un cierto químico supone una amenaza para la salud de todos nosotros, y que no hay ninguna duda respecto del remedio apropiado, que no es sino el cese del uso de dichos productos (asumo que la carga que esto involucra es la misma para todos, y omitiré por el momento la pregunta por los efectos que tiene el uso del químico en las vidas de aquellas personas que trabajan en la industria que lo produce o que venden productos que lo contienen). Si, reconociendo este hecho, constatamos que la mayoría de las personas han adoptado una política de no usar estos químicos, entonces, creo, sería incorrecto que yo continuara con su uso. (Para ponerlo en términos de mi propia concepción de la moral, un principio que permitiese a las personas excluirse de esta práctica establecida sería uno que podríamos razonablemente rechazar $^{1}$.)

La práctica de abstenerse de usar los productos que contienen el químico dañino es lo que aquí voy a llamar una "institución”. Una institución existe allí donde las personas no sólo actúan en conformidad con ciertos estándares, sino que además tienen la convicción de que muchos otros también lo hacen. Ésta es una concepción muy abstracta de institución, pero

${ }^{1}$ Defiendo esta concepción contractualista de la moral en What We Owe to Each Other (Cambridge, Mass: Harvard University Press, 1998). [Edición en castellano: Lo que nos debemos unos a otros: ¿Qué significa ser moral? (Barcelona: Paidós Ibérica, 2003)] 
asumiré en adelante que los Estados, sistemas jurídicos, universidades y otras entidades que normalmente llamamos instituciones son instituciones en este sentido abstracto, aun cuando son mucho más complejas que la institución simple de mi ejemplo.

La tesis que presenté arriba, sobre lo incorrecto de usar productos que contienen el químico dañino cuando otros omiten su uso reconociendo el daño involucrado, depende de la existencia de una institución; algo que no podemos afirmar de la prohibición de uso de fuerza letal, aunque en ambas ideas subyace un principio de moral individual. La filosofía política, como habré de entenderla, se preocupa de estándares morales para la valoración de las instituciones mismas; por ejemplo, como justas o injustas ${ }^{2}$. Las conclusiones a las que llega pueden tener implicancias en la determinación de lo que los individuos debieran o no hacer, pero no son en principio conclusiones de este tipo, sino más bien conclusiones relativas a las instituciones.

Ambos tipos de conclusiones, a las que llegan estas dos disciplinas, parecen ser juicios morales en algún sentido amplio. ¿Pero qué sentido es éste? Ésta es la primera pregunta que quisiera abordar sobre la relación entre las disciplinas: ¿En qué sentido son las preguntas, con las que ambas deben lidiar, preguntas morales? La segunda interrogante se refiere a la relación entre los dos objetos de estudio. La cuestión aquí pasa por determinar las implicancias que tienen las conclusiones sobre la moral de las instituciones para la cuestión de la permisibilidad o impermisibilidad de la conducta individual, y si el contenido de las conclusiones sobre la moral de las instituciones se satisface con estas implicancias, o bien incorpora algo más.

\section{DIVERSAS COMPRENSIONES DE LA MORAL (UNA PEQUEÑA DIGRESIÓN)}

Creo que el concepto "moral" se usa ampliamente sin una clara y compartida comprensión de su contenido. Esto ocurre no sólo en el discurso público sino también en discusiones académicas. Hay un acuerdo generalizado, creo, en torno a que la moral reclama ser algo importante: que los estándares morales supuestamente son tales que cualquier persona tiene

${ }^{2}$ Esto es lo que John Simmons denomina preguntas sobre la justificación de instituciones. Véase Simmons, "Justification and Legitimacy", Ethics 109 (1999): 739-771. 
buenas razones para adoptarlos seriamente como pautas de conducta. Pero incluso aquellos que creen en su importancia tienen desacuerdos en torno a las razones que tenemos para ello. Y muchos de los que tienen mayor claridad tienen desacuerdos sobre cuáles son esas razones específicas.

Una manera de reconocer lo que identificamos como razones en este sentido será concentrarnos en el tipo de aflicción que experimentamos (y que entendemos apropiada) cuando nos percatamos de que hemos sido incapaces de satisfacer los requerimientos de la moral en cierto caso particular. He aquí lo que llamo el "test del remordimiento". El carácter de este remordimiento nos informa sobre la naturaleza de las razones que adoptamos para fundamentar los estándares que infringimos. Identificar qué entendemos por estas razones es, por supuesto, sólo el primer paso de un proceso reflexivo. Debemos luego preguntarnos si son, de hecho, buenas razones o si, como diría Nietzsche, no lo son, y la susceptibilidad a ellas es una enfermedad que debiéramos intentar precaver.

Creo que este proceso de reflexión revela dos formas de diversidad. Primero, distintas personas tratan la moral de modo distinto pues la entienden respaldada por razones diferentes (en algunos casos buenas razones, en otros casos no). Pero, en segundo lugar, el test del remordimiento, me parece, indica que yo trato el concepto "moral" como aplicable a estándares respaldados por razones muy diversas, y por buenas diversas razones. Conjeturo que esto es cierto respecto de otras personas también, y quiero explorar brevemente esta segunda forma de diversidad.

El componente central de la moral individual tal y como yo la entiendo - la llamo la moral de lo que nos debemos los unos a los otros- es algo que tenemos razones para cuidar porque tenemos razones para preocuparnos por nuestras relaciones con otros, en un ámbito en que la justificabilidad de las acciones juega un rol importante. Existe, creo, una versión correlativa en la moral de las instituciones, consistente en estándares que las instituciones deben satisfacer si pretenden justificarse ante aquellos sujetos respecto de los cuales reclaman aplicación. Mucho depende, por cierto, de la forma particular de justificación involucrada. Someramente, la entiendo como justificación en el sentido de los intereses de los afectados. En lo que sigue me concentraré en esta forma de moral individual y de moral de las instituciones, y es en este sentido que las presento a ambas como formas de moral. Injustos morales, del tipo que tengo en mente, se pueden identificar gracias a la presencia de una forma particular de remordimiento: el senti- 
miento de enajenación del resto, sentimiento que se sigue de constatar que se les ha tratado de un modo que no podría ser justificado ante ellos, o que se participa con ellos de una institución que no podría ser justificada ante ellos (incluso dependiendo de su participación en esta institución).

Pero no sólo un déficit de esta naturaleza cuenta como ese tipo de cosa que comúnmente llamamos injusto moral, o un acto moralmente incorrecto (morally wrong). Varios tipos de faltas personales, como lo es dejar de trabajar duro, o de esforzarse por lo que es valioso, por ejemplo, son plausiblemente llamadas faltas morales aun cuando no involucran falencias relativas a lo que debemos a otros.

En Ana Karenina, Tolstoi describe a Lievin retornando de un día de trabajo en los campos junto a sus campesinos, sintiéndose moralmente superior a su hermano, quien se ha quedado en casa, leyendo. Al leerlo nos hace sentido. ¿Pero cuál es la idea de moral presente aquí? Puede ser que Lievin se sienta menos enajenado que sus campesinos porque ha estado (al menos en un sentido simbólico) compartiendo el trabajo con ellos. Aquí se invocaría la moral en el sentido restringido descrito más arriba. Pero podemos leer el pasaje y pensar que es simplemente mejor participar de un trabajo físico, bueno y honesto, a estar tirado en el sofá todo el día con un cigarrillo y una novela.

La última idea forma parte de lo que Bernard Williams, en su Ethics and the Limits of Philosophy, denominó ética — la cuestión de cómo es mejor vivir - en oposición a la moral, que se preocupa de nuestras obligaciones con otros. Hasta la contribución de Williams, los conceptos "moral" y "ética" eran, al menos en la mayoría de los círculos académicos, usados de modo más o menos indistinto. El hecho de que un curso de filosofía fuera llamado "Ética" o "Filosofía moral" no generaba la expectativa de que hubiera diferencia en el contenido, aunque sí se sabía que era improbable que tuviera algo que ver con el sexo. Esto es, aunque ciertas conductas que involucran actos sexuales, como una violación, fueran consideradas moralmente incorrectas en los términos con los que trata un curso como ése, esto sólo sería así porque se trata de especies de un género de injustos, como es el caso del uso de la fuerza, la violencia o el engaño. Cuestiones relativas al acto sexual en sí mismo —el número de personas involucradas en el acto, si se trata de hombres o mujeres, las partes del cuerpo utilizadas, etcétera - serían moralmente indiferentes, en el sentido de "moral" que se va a discutir. 
Afuera en el mundo, por supuesto, las cosas son muy distintas. Si leemos en el periódico sobre la moral de un político, sabemos inmediatamente que tiene que ver con sexo. Y si es la ética lo que se menciona, entonces tiene que ver con dinero. Me parece que esta forma popular de entender la distinción entre ética y moral puso las cosas al revés. Si es que hay una diferencia como la que sugirió Williams, y yo creo que la hay, una diferencia, digo, entre cuestiones de obligación y cuestiones más amplias sobre el valor de la vida y cómo vivirla; y si es que existen asuntos morales relacionados con el sexo que van más allá de los que nos debemos unos a otros, como creo que los hay, entonces estos últimos son asuntos de ética y no de moral. Tienen que ver con lo que vale la pena valorar y cuánto, antes que con la definición de las acciones permitidas o prohibidas. Esto puede sonar a un ejercicio pedante de limpieza terminológica, pero es verdaderamente importante. Suena melodramático decir que muchas vidas se han arruinado por la amplia confusión en torno a esto, pero creo que efectivamente eso es lo que ha ocurrido. Ésa es, en todo caso, materia de otro trabajo ${ }^{3}$.

He mencionado el sexo y el trabajo duro como dos objetos de discusión moral usando un sentido de "moral" que excede los términos de lo que nos debemos unos a otros. Otro tópico de debate es la lealtad personal con una causa o institución. Esta lealtad, que probablemente podemos llamar una virtud moral, no es requerida por los principios que especifican lo que les debemos a otros. Más bien es un asunto de perseverancia en los compromisos que uno asume con una causa o institución que vale la pena mantener. Una persona que resulta ser desleal queda expuesta a la crítica por parte de otros, que siguen comprometidos con la causa o institución, no sólo por el déficit que muestra en lo que les debe a ellos, sino también por el insuficiente compromiso que muestra con la causa o institución en cuestión. Pero éste es un déficit moral sólo en la medida en que vale la pena mantener esa forma de compromiso con dicha causa o institución.

El punto de esta discusión sobre las diversas comprensiones del concepto "moral" no es sólo mostrar que distintas personas lo usan con distintas ideas en mente sino también, como ya he dicho, que cada uno de nosotros lo usa para referirse a (lo que yo sugiero veamos aquí como el reflejo de) una diversidad de valores. Cuando reconocemos esta última diversidad la pregunta deja de ser: “¿Qué concepción acierta en capturar lo que la mo-

${ }^{3}$ El título de ese otro trabajo podría ser "Desde un punto de vista moral y ético, el sexo es como el trabajo". Dejo como tarea determinar por qué esto es así. 
ral realmente es?”; y pasa a ser, en cambio: “¿Qué son estos valores, cuáles vale la pena proteger, y cómo encajan todos juntos?".

Correspondiente con esta diversidad de modos de comprender la moral individual existe una diversidad de formas de crítica moral a las instituciones. Como ya he dicho, la moral institucional que discutiré aquí se preocupa de la justificabilidad de las instituciones frente a los individuos, sobre la base de sus reclamaciones individuales. Pero tal y como puede expresarse una crítica respecto de la acción de individuos, que podemos plausiblemente llamar "moral" sobre la base de su capacidad de responder al estímulo de valores (que no surgen de sus obligaciones con otros), también las instituciones pueden ser criticadas con arreglo a los fines valiosos que promueven, el tipo de individuo que tienden a producir, o el tipo de vida que instan a llevar.

John Rawls desarrolla lo que aquí estoy identificando como una versión individualista de la moral de las instituciones cuando expone, al principio de A Theory of Justice, su concepción de la sociedad como un "esquema cooperativo para la ventaja mutua" diseñado para promover el bien de los individuos que participan y que tienen fines y propósitos diversos4. Una concepción de la justicia, como Rawls la entiende, supone un set de estándares destinados a evaluar las reclamaciones o exigencias que los individuos pueden dirigir a un "sistema cooperativo", en este sentido rawlsiano. Una concepción tal afirma aquello que Rawls identifica como "los vínculos de la amistad cívica”, vínculos que limitan la persecución de los fines diversos de los individuos. Tal forma de entender la justicia $-\mathrm{y}$ aquello que yo llamo la moral de las instituciones- se distingue claramente de aquella que sería apropiada para la sociedad concebida como un grupo de individuos unidos en la persecución de algún objetivo o valor compartido.

Instituciones en este último sentido incluyen universidades, partidos políticos y grupos de acción, como también algunos negocios. Éstas nos invitan a confiar en ellas y apoyarlas de distintas maneras por cuanto están guiadas por valores importantes. ¿Qué significa que una institución esté guiada por valores? Asumo que significa lo siguiente: las instituciones están conformadas por individuos a los que les asignan varios roles y responsabilidades. Decir que a una institución la guían ciertos valores es decir que

${ }^{4}$ John Rawls, A Theory of Justice, revised edition (Cambridge, Mass: Belknap Bress, 1999), 4-5. [Edición en castellano: Fondo de Cultura Económica, sexta reimpresión, 2006, 18-19.] 
se organiza de tal forma que se mostrará responsiva a estos valores si los individuos a quienes se asignan los roles cumplen con lo que les está asignado. Si es que esto llega o no llega a ocurrir depende del modo en que la institución esté organizada, y de lo que podríamos llamar su "economía de influencia" como propiedad interna, esto es, el patrón motivacional al cual responden los individuos que forman parte de la institución5.

Entonces, a modo de ejemplo, diremos que una aerolínea está guiada por los valores de la seguridad de sus pasajeros si se encuentra organizada de modo tal que la información sobre las condiciones del clima y condición mecánica del avión llega a los individuos que toman decisiones sobre los vuelos, y además los individuos que asumen esta tarea están motivados como para tomar las decisiones apropiadas sobre si volar o no, sobre la base de esta información. Cuando decido volar, confío en que la aerolínea se guía por este valor.

De modo similar, la Universidad Harvard dice estar guiada por el valor consistente en producir investigación académica de alto nivel e impartir educación de elevada calidad. Invita a las personas a confiar en ella enviando a sus hijos a estudiar allí y depositando su confianza en la investigación que Harvard produce. También invita a la lealtad, esto es, invita a los aportantes a comprobar que vale la pena su aporte, y a aquellos que trabajamos en esta universidad nos invita a comprobar que vale la pena trabajar duro aquí y sacrificar otros compromisos para hacer bien nuestro trabajo. La corrupción institucional ocurre cuando la economía de influencia interna de una institución es tal que no opera del modo requerido para responder a los valores que, se supone, han de proveer de razones a otros para interesarse y preocuparse por la institución.

Así entendidas, la corrupción, la confianza y la lealtad son nociones normativas. Esto es, dicen relación con las razones que las personas tienen para comportarse de cierto modo y adoptar ciertas actitudes. Estas nociones también parecen ser morales, pero ¿en qué sentido? Un elemento moral presente es la honestidad: la pregunta es si las instituciones realmente hacen lo que afirman hacer, mientras nos invitan a confiar en sus acciones, o bien llevan adelante una forma de engaño que los estándares morales prohíben. Aunque hay más que esto. Si yo fuera a suprimir o suspender la confianza y lealtad depositada en una institución - ya sea una aerolí-

${ }^{5}$ Lawrence Lessig, Memorandum of October 9, 2009, http://www.ethics.harvard.edu/images/resources/pdfs/v1.0.pdf 
nea, Harvard o la FDA-, podría ser porque creo que ha actuado de modo deshonesto, pero la principal razón no surgiría del hecho de haber sido engañado sino del hecho de que las instituciones no han respondido a los valores involucrados. Esto me importa no sólo porque no deseo ser víctima de engaños sino también porque me importan los valores. De modo que la principal fuente de la fuerza normativa de las nociones de confianza, lealtad y corrupción viene dada, en este contexto, por los valores particulares involucrados, ya sea se trate del valor de la seguridad personal, la calidad intelectual u otro.

Esto es paralelo a lo afirmado más arriba sobre la deslealtad en tanto falta individual. Si una persona que está comprometida con cierta causa critica a otra por ser insuficientemente leal a aquélla, esto puede involucrar en subsidio el cargo "decepcionar al resto de nosotros" por esta falta de compromiso. Pero ésta no es la cuestión principal. La lealtad que se espera (y en este caso se acusa que falta) no se deja ver en principio como un sentido de obligación para con el resto de nosotros, que honramos el mismo objetivo. La lealtad en este caso se muestra en primera instancia vinculada a la motivación con el compromiso asumido con el objetivo mismo.

De este modo, la relación (con fuerza normativa) que existe allí donde hay lealtad y confianza hacia una institución, y que se pierde cuando éstas se menoscaban por la corrupción es, para decirlo de alguna forma, vertical. Se trata de una relación entre un individuo y una institución, derivada de cierto valor respecto del cual la institución se presume responsiva. Esto contrasta con los vínculos morales horizontales entre individuos que operan como miembros cooperativos.

\section{UNA CUESTIÓN PRELIMINAR SOBRE LA MORAL DE LAS INSTI- TUCIONES Y SU RELACIÓN CON LA MORAL INDIVIDUAL}

Hasta ahora me he preocupado de la pregunta: "La moral individual y la moral de las instituciones, ¿en qué sentido de 'moral' tratan con cuestiones 'morales'?" He identificado una comprensión de lo moral en que ambas convergen. Mi segunda pregunta sobre la relación entre la moral individual y la moral de las instituciones tiene que ver, primero, con cómo las conclusiones morales de este tipo, relativas a instituciones, llevan a conclusiones morales sobre lo que los individuos deben o no hacer; y en segundo lugar, con la cuestión de si estas conclusiones sobre la moral individual agotan el contenido normativo de las conclusiones sobre la moral de las instituciones. 
Desarrollaré estas preguntas dentro del marco de la teoría de John Rawls, pues éste ofrece una comprensión elaborada de todas las nociones relevantes: de la justicia como la noción central de la moral institucional, y de la relación entre la justicia de las instituciones con los deberes de los individuos. Al seguir su teoría no estoy usándola como un argumento de autoridad, ni presumiendo la exactitud de su visión. Puede ocurrir que al evaluar las tesis con que nos compromete la propuesta de Rawls decidamos cuestionar sus asunciones básicas y busquemos una propuesta alternativa.

Los principios de justicia, según Rawls, son estándares para evaluar las reclamaciones de los individuos contra las instituciones, en particular contra lo que él llama la "estructura básica" de una sociedad. El papel de estos principios es determinar la validez de las demandas que persiguen el cambio o la reforma de esas instituciones. Al interior de lo que Rawls llama una "sociedad bien ordenada" sus miembros comparten un "sentido de la justicia". Esto significa que ellos están de acuerdo en ciertos principios de justicia que los motivan. Además, en la sociedad bien ordenada, los ciudadanos creen, correctamente, que sus instituciones satisfacen estos principios. En una primera instancia podemos entender la motivación por un sentido de justicia como una tendencia a cumplir con las instituciones que uno cree son justas, a exigir que se hagan cambios cuando uno cree que son injustas, y a consentir en esos cambios cuando son demandados por otros. Esto encaja con el postulado de Rawls sobre un sentido compartido de justicia cual un "aparato equilibrante" ${ }^{\text {. }}$. Aun las instituciones justas, afirma, pueden devenir en injustas por un cambio en las condiciones. Cuando esto ocurre, el sentido de justicia que los ciudadanos de una sociedad bien ordenada comparten los motiva a demandar, trabajar y aceptar los cambios necesarios para devolver sus instituciones a la justicia.

Nuestro sentido de justicia es lo que gobierna ese sentimiento de angustia y desconcierto, tal como lo describí en la sección anterior, y que aparece allí donde constatamos la manera en que nuestras instituciones injustas tratan a otros, quienes deben acatarlas de modo que estas instituciones funcionen y satisfagan nuestras necesidades. En las palabras de Rawls arriba expuestas, las instituciones que no son completamente justas lesionan los "vínculos de amistad cívica", y la aflicción descrita es producto de la constatación de esta lesión.

\footnotetext{
${ }^{6}$ Rawls, A Theory of Justice, 458. [Edición en castellano: 471-472.]
} 
Esta aflicción forma parte de la vida moral e institucional y nos es por tanto familiar, pero ¿cuál es su significado práctico? Rawls afirma que este sentimiento nos incentiva a llevar a cabo lo que sea necesario para hacer más justas nuestras instituciones: tomarse en serio los estándares de justicia supone tomarlos como guías para la acción al momento de emitir un voto como ciudadanos y en cualquier otro momento en el que nuestras acciones pueden tener efectos en los arreglos institucionales. Lo triste es que generalmente nos encontramos viviendo bajo - y dependiendo de - instituciones que no satisfacen estándares de justicia, lo que se encuentra fuera de nuestra capacidad de intervención. Estamos atrapados en estas instituciones que gobiernan nuestras vidas, en una relación moralmente inaceptable con aquellos que están involucrados o afectados por ellas.

Puede ser provechoso detenerse aquí para apreciar el papel esencial que juegan las instituciones en esta forma particular de aflicción. Si escucho que alguien muy lejos está abusando de otra persona, puedo sentir indignación. Pero ese hecho no me involucra. En cambio, si constato que una institución en la que confío (aun cuando no jugué ningún rol en su creación ni tengo el poder para cambiarla) opera por medio de la explotación de personas en cierto lugar, este hecho tampoco me involucra, y sin embargo da origen al tipo de aflicción que estoy describiendo.

Una forma similar de aflicción puede originarse en la dimensión de la moral individual. El utilitarismo es frecuentemente criticado por lo inaceptable de sus exigencias. No obstante, si tomáramos en consideración el apuro de todas las personas del mundo que están en una situación desesperada (como lo haría un utilitarista), estando su auxilio a nuestro alcance, parecería que cualquier consideración posible de moral individual estaría en condiciones de descubrir o formular estándares de conducta individual en cuya satisfacción estaríamos fallando, y que seguiríamos defraudando (dada nuestra preocupación por nuestra propia satisfacción y la de aquellos cercanos a nosotros). Si esto es así, entonces tanto la moral individual como la moral de las instituciones tienen su lado doloroso.

Estas formas de aflicción no siempre son distintas. El hecho de que existan exigencias desde la moral individual que probablemente defraudaremos - como aquellas relativas a deberes de asistencia al necesitado, lejano y no tan lejano- permite constatar problemas que requieren una solución institucional. De modo que el dolor de constatar el déficit en la expectativa en realidad es un caso del primer tipo de aflicción mencionado 
(el de la participación en una institución que no satisface los estándares de justicia).

Los ejemplos señalados involucran nuestra relación con los más pobres en otras partes del mundo. Pero el análisis también se aplica a nivel doméstico. En Estados Unidos dependemos de las personas pobres para recoger nuestra fruta tanto como dependemos de las personas pobres en cualquier otra parte para recoger nuestro café. De modo que se presentan los mismos problemas.

La aflicción que sentimos en estos casos se parece, en cierta manera, a ese remordimiento que surge con la infracción de un estándar de moral individual. En ambos casos nos percatamos de que estamos conduciendo nuestras relaciones con otros de una forma que no podría ser justificada ante otros de manera aceptable. Pero en el caso de la moral personal lo que daña nuestra relación con otros es nuestro comportamiento y la falta de preocupación por otros que expresan nuestras acciones. La aflicción que se sigue de injustos propiamente institucionales, por el contrario, no depende ni de nuestro comportamiento ni de nuestra actitud hacia otros. Puede surgir simplemente del hecho de que participamos con otros de una institución que no puede justificarse ante ellos mismos. La necesidad de supervivencia puede darles a otros razones para comprometerse con la institución, pero existe un constreñimiento injustificable que afecta su proceso de decisión. Podemos también, por cierto, sentir aflicción por el hecho de que nuestro bienestar actual sea fruto de injusticias pasadas. Mas la aflicción que surge de la injusticia presente es diferente, porque surge en un contexto en el que dependemos de la continua participación injusta, en cierta institución, por parte de ciertos individuos con quienes nos relacionamos ${ }^{7}$.

Algunos podrían decir que, en la medida en que las imperfecciones de este tipo son inevitables, una aflicción a causa de ellas no es más que un acto de problematización ociosa. Pero parece falto de corazón dejar de reparar en ello. El emotivo parágrafo final de $A$ Theory of Justice lo entiendo como la expresión de un deseo por una condición en la que esa forma de aflicción pueda, en una conciencia limpia, ser evitada. Por más elocuente que nos parezca ese pasaje, todavía podemos preguntarnos si la justicia, en el sentido ideal que a Rawls le preocupa, tiene algo que decirnos sobre cómo pensar y cómo actuar en las condiciones en las que de hecho vivimos.

${ }^{7}$ Agradezco a un árbitro anónimo de Estudios Públicos por señalarme la necesidad de tratar esta cuestión de intertemporalidad. (N. del A.) 


\section{JUSTICIA Y DEBERES DE CUMPLIR CON LAS INSTITUCIONES}

Hasta aquí lo que se ha dicho sólo se refiere al rol motivacional del sentido de la justicia. Nada se ha dicho sobre la moral individual, sobre el deber o la obligación. Ahora me preocuparé de la cuestión sobre cómo las conclusiones respecto de la justicia o injusticia llevan a conclusiones referidas al deber individual; o sea, me referiré al vínculo entre la moral de las instituciones y la moral individual. En el trabajo de Rawls este vínculo se forja en torno a lo que él denomina el "deber natural de justicia". Este deber, afirma, "nos exige apoyar y obedecer a las instituciones justas existentes que nos son aplicables. Nos constriñe también a promover acuerdos justos aún no establecidos, al menos cuando esto pueda hacerse sin demasiado costo para nosotros" ${ }^{8}$. Discutiré en lo que sigue las dos partes de este deber, comenzando por el deber de cumplimiento (duty to comply).

La lógica de este deber opera así: si cierta institución es justa, entonces los individuos no tienen razones válidas para objetarla o exigir cambios. Parece seguirse de esto que tampoco tienen justificación para dejar de realizar aquello que la institución exige. Esto puede parecer apresurado, pero explicaré más adelante por qué creo que no lo es. Lo que Rawls afirma es que tenemos un deber de cumplimiento con las instituciones que existen, que son justas y que se aplican a nosotros. Para lograr comprender lo que está en juego en estas tres condiciones, y la relación entre ellas, será de utilidad volver a mi ejemplo de los químicos dañinos.

Afirmé que si la mayoría adopta una política de no uso de estos químicos entonces, me parece, sería incorrecto que yo siguiera usándolos. Esta conclusión se encuentra en el terreno de la moral individual, esto es, se trata de una conclusión sobre lo que está moralmente permitido a un individuo hacer. Pero es dependiente de otra conclusión, la cual es propia de la dimensión que aquí estoy llamando moral de las instituciones, puesto que depende de que la práctica en cuestión no sólo exista sino que además sea justa. Debemos detenernos un minuto y considerar lo que esto significa. Parece natural concebir en un principio a la justicia de una institución en términos puramente distributivos. Así, en nuestro ejemplo, la práctica sería injusta si (en ausencia de una justificación adicional) exigiera solamente a ciertas personas abstenerse de usar los productos que contienen el químico y permitiera su uso a otros. De modo más general, diríamos que una prác-

\footnotetext{
${ }^{8}$ Rawls, A Theory of Justice, 99. [Edición en castellano: 116.]
} 
tica es justa si distribuye los beneficios y cargas de un modo equitativo. Esto sería correcto si "beneficios", "cargas" y "equitativo" se interpretan de modo suficientemente amplio. Pero poner las cosas así puede desviar nuestra atención de la cuestión de si los beneficios que la práctica trae, independientemente de su distribución equitativa, son lo suficientemente importantes para justificar las exigencias que impone, aun cuando éstas sean las mismas para todos ${ }^{9}$.

Escogí el ejemplo del químico dañino porque lo trato como el caso en que esta exigencia de suficiente importancia se satisface. Un ejemplo más claro, o más dramático, sería el de un sistema de cooperación destinado a mantener los diques que evitan que el mar nos lleve a todos. Hay un contraste entre estos ejemplos, y otro ejemplo de la vereda opuesta, como el que ofrece Robert Nozick: el del vecindario y su sistema de megafonía ${ }^{10}$. Supongamos, dice Nozick, que hay un sistema de megáfonos en nuestro vecindario y que a algunos vecinos se les ocurre la idea de usarlos para emitir una programación de modo regular con el contenido que ellos quieran — noticieros, música, poesía u otra cosa - y que luego postean una lista asignando a cada miembro un lapso de tiempo por el cual es responsable. Pasan un par de semanas hasta que llega el momento de tu lapso de tiempo asignado, y concluyes que disfrutas mucho de esta institución. Aun así, afirma Nozick, no tienes la obligación de asumir tu turno cuando llegue el día que te corresponde.

Esto parece ser así, creo yo, puesto que los beneficios que la institución genera no son lo suficientemente importantes como para justificar, por ejemplo, coaccionar a todos los vecinos a participar. Una institución justa de este tipo tiene que ser voluntaria. Esto es, debería permitir a los vecinos salirse si así lo eligen. Nozick sugiere que la práctica que él describe es justa, teniendo en mente, supongo, el hecho de que el trato que reciben los

${ }^{9}$ En lo que sigue asumiré que los beneficios en cuestión son beneficios para individuos, específicamente aquellos que participan en el proceso, aunque esta última asunción no será crucial. Esto hace del deber en cuestión un asunto de obligación horizontal. Es interesante la pregunta de si, y cuándo, las instituciones pueden ser justificadas de la manera en que aquí presento la cuestión, teniendo en consideración el hecho de que necesitamos que promuevan cierto valor impersonal. La idea de que instituciones coercitivas no pueden ser justificadas, al menos en este sentido, yo supondría que es una forma generalizada del "principio del daño" de John Stuart Mill.

${ }^{10}$ Robert Nozick, Anarchy, State and Utopia (Oxford: Blackwell Publishers, 1999), 90-95. 
vecinos es igualitario. Mas la práctica no es justa si impone obligaciones injustificables. Esto es lo que nos interesa de su argumento.

Lo anterior nos trae a la tercera condición que Rawls estipula: que la institución se aplique a alguien. ¿Qué significa, en términos relevantes, que una institución se aplique a alguien? Dada la condición previa —que la institución sea justa-, creo que podemos interpretar esta tercera condición como estipulando simplemente que la institución afirma que se aplica a alguien. La pregunta entonces es ¿respecto de quién puede una institución, con justicia, afirmar que se aplica? La respuesta, creo, es que una institución justa puede afirmar que se aplica sólo a aquellos cuya participación es necesaria para generar los beneficios en cuestión, y puede afirmar esto sólo si los beneficios tienen la suficiente importancia para justificar el constreñimiento que supone la ejecución.

Esta afirmación clarifica lo que expresé antes con relación a que podía parecer un paso muy apresurado el que se hacía desde la constatación del hecho que una institución es justa — que nadie tiene un reclamo válido que hacer contra ella - a la conclusión de que las personas están obligadas a cumplir con ella. Se trata de un paso sensato, y por tanto no es apresurado, toda vez que, como ya vimos, una reclamación posible que los individuos pueden dirigir a una institución es que ésta no puede con justicia aplicársela a ellos. La explicación parece validar el paso por la vía de trivializarlo, o bien parece obligar al argumento a dar un paso atrás hacia la cuestión de cómo debe ser una institución para que sea justa. No obstante esto, me parece que la reflexión en torno a la diferencia entre el ejemplo del químico dañino y el ejemplo del sistema público de Nozick muestra que es aquí el lugar a la que la discusión pertenece.

\section{INSTITUCIONES INJUSTAS}

Parece que hemos llegado a la conclusión de que la justicia de una institución es condición suficiente para que exista un deber de cumplimiento para con ésta ${ }^{11}$. ¿Es también condición necesaria? ¿Es que no existe un deber de cumplimiento para con instituciones injustas? Esto parece plausible para el ejemplo del sistema público del vecindario. Pero ése era un caso es-

${ }^{11}$ En los términos del trabajo de John Simmons citado ("Justification and Legitimacy"), esto da cuenta del hecho de que una respuesta a la pregunta por la justificación resuelve además la pregunta por la legitimidad. 
pecial, porque la injusticia en cuestión simplemente era la ausencia de la opción de salirse, y porque el beneficio no era particularmente alto. Las cosas serían distintas, creo, dado el caso de un esquema injusto en la mantención de los diques. La justicia no parece siempre tener el efecto de eliminar el deber de cumplimiento. Muy pocas instituciones sociales de gran magnitud (las que Rawls llama "estructuras básicas"), si es que alguna, son completamente justas, mas no parece seguirse de esto que las personas se libren por eso de la obligación de cumplir con sus exigencias. De modo que al afirmar que una institución está legitimada cuando los que viven bajo sus condiciones tienen un deber de cumplir con sus exigencias, lo que estamos haciendo es elevar la justicia como estándar por encima de la mera legitimidad.

Pero la legitimidad, entendida según una cuestión de todo o nada, no se muestra como un concepto adecuado para abarcar el rango de casos que debieran ser de nuestro interés. Consideremos lo siguiente: los deberes de cumplimiento varían, dependiendo de la posición del individuo en la institución. Si la práctica establecida de frenar el uso de los productos que contienen el químico dañino fuera injusta, no se seguiría de ello la ausencia de un deber de cumplimiento de la práctica por parte de los beneficiarios de dicha injusticia. En segundo lugar, aun cuando la injusticia de una práctica cambie la situación moral de aquellos que son víctimas de la injusticia, no lo hará sólo por la vía de eliminar cualquier deber de cumplimiento de los requerimientos de la práctica.

Esto es aun más claro en el caso de las víctimas de la injusticia en sociedades reales. Consideremos, por ejemplo, uno de los grupos peor situados de nuestra sociedad, las personas que nacen y viven en los guetos negros urbanos ${ }^{12}$. Estas personas crecen en condiciones que les presentan muy pocas oportunidades de desarrollo económico, un poder político severamente limitado y oportunidades educacionales tan pobres que hacen improbable que puedan superar estas condiciones. Las instituciones que ponen a las personas en estas condiciones son seriamente injustas, pero esta injusticia no anula el deber de estas personas de obedecer el derecho. Sus efectos son más complejos.

Necesitamos, entonces, mirar más de cerca los modos en que el hecho de que una institución sea injusta afecta la situación moral de aquellos a

${ }^{12}$ Lo que diré en los próximos parágrafos es deudor del mucho más detallado estudio de Tommie Shelby en "Justice, Deviance and the Dark Ghetto", Philosophy \& Public Affairs 35 (2007): 126-160. 
quienes se aplica. Me aproximaré a esta cuestión usando dos estrategias de modo más o menos simultáneo. La primera es considerar lo que la segunda parte del deber natural de justicia de Rawls tiene que decir sobre casos como éstos. La segunda, situada en el fondo de la cuestión, es preguntarme - cual un contractualista - qué principios, gobernando la conducta de personas que viven bajo instituciones injustas, serían principios que nadie podría razonablemente rechazar.

La segunda parte del deber natural de justicia de Rawls "nos constriñe a promover acuerdos justos aún no establecidos, al menos cuando esto pueda hacerse sin demasiado costo para nosotros". Este principio resuelve lo que de otro modo habría sido una paradoja en lo que respecta a las "instituciones aún no establecidas". Volvamos nuevamente al caso del químico peligroso ${ }^{13}$. Si se establece una práctica de abstención de uso de productos que contienen el químico, entonces dejar de cumplir resulta incorrecto. Pero si la gran mayoría sigue usando los productos, a pesar de los efectos dañinos conocidos, ¿sigue siendo incorrecto que un individuo los use? Si dejar de usarlos supone asumir algún costo, y el uso por parte de un solo individuo no supone una diferencia significativa en el peligro a la salud, entonces parece haber una paradoja. Por un lado, parece inútil que un solo individuo renuncie al uso de los productos sin ningún beneficio significativo. Por el otro, el uso generalizado viola un principio que nadie podría razonablemente rechazar, y causa un daño serio. Parece entonces claramente incorrecto afirmar que nadie está haciendo nada malo continuando el uso. La pregunta es: ¿está o no la prohibición de uso condicionada a que exista a su respecto un cumplimiento generalizado? Llamaremos a esto el "dilema del no-cumplimiento".

La apariencia de dilema se explica por la presencia de sólo dos alternativas: cumplimiento y no cumplimiento. La tercera alternativa sería la siguiente: cuando existe un no-cumplimiento generalizado, lo que los principios no-rechazables exigen es que hagamos saber a otros nuestra disposición a validar un principio que prohíba el uso de los productos, e insistir en la importancia de este camino. Esto puede incluir la acción de abstención del uso del producto por parte de nosotros mismos, como un ejemplo para los demás y como señal de buena fe. Si una persona hace esto, y persiste el no-cumplimiento generalizado, entonces no será incorrecto que esta persona deje de cumplir, si el cumplimiento implica un costo personal signi-

${ }^{13}$ La institución de este ejemplo no es una "estructura básica" en el sentido de Rawls. Volveré luego a la diferencia que esto hace. 
ficativo. Esta alternativa se ve expresada en la cláusula relevante del deber natural de justicia de Rawls.

Pasando ahora al caso de instituciones que existen pero que son injustas, recordemos que los principios de justicia, como los entiende Rawls, son estándares evaluativos de estructuras básicas, y en particular son evaluativos de reclamaciones de cambio o reforma. Rawls describe el sentido de justicia compartido como una fuente de motivación "equilibrante". Ahora tratamos los principios de justicia como una fuente de justificación, en vez de una mera fuente de motivación, como lo es el sentido.

Consideremos primero la posición de los partícipes de una institución injusta que se benefician del hecho de que es injusta. Dado que las reclamaciones de cambio o reforma de aquellos a quienes la institución trata injustamente son válidas, sería incorrecto que los beneficiarios de la injusticia se resistieran a los cambios demandados. El deber natural ralwsiano va más lejos y exige que ellos se esfuercen por promover dichos cambios cuando "esto pueda hacerse sin demasiado costo para nosotros". Esto parecía correcto para el caso de instituciones "aún no establecidas" y parece correcto también aquí. Pero la pregunta es cómo medimos los "costos para nosotros". En particular, ¿cuenta como costo la pérdida de los beneficios injustamente adquiridos? La respuesta que parece ser la correcta, y parece seguirse de la propuesta de Rawls, es que no. En la medida en que sea válida la demanda que persigue el que dichos beneficios no sean entregados (que se sigue del hecho de que son injustos), ¿cómo puede existir una objeción válida a renunciar a ellos?

Volvamos a la posición de aquellos que, como los pobres de los guetos, son víctimas de instituciones injustas. Estas personas, según ya hemos dicho, pueden reclamar por cambios a la institución, para así hacerla más justa. Pero estas demandas no serán escuchadas, y no tendrán ningún "efecto equilibrante", sin medios para hacerlas efectivas. En el caso de una práctica aislada, como la que imagino en mi ejemplo del químico peligroso, el único medio disponible sería la expresión pública, respaldada quizás por amenazas para asegurar el cumplimiento. Si las expresiones públicas resultaran inútiles, entonces cesar el cumplimiento estaría justificado como el único medio para lograr el objetivo, y ya en este punto parecería que aquellos que se benefician de la injusticia del esquema no podrían reclamar la pérdida de los beneficios. Esto es, no podrían ya reclamar por el hecho de no seguir recibiendo los beneficios de la institución sin soportar los costos. 
Pero, si el número de personas tratadas injustamente es considerable, de modo tal que su salida de la institución perjudica la efectividad de la institución como una forma de protección contra el daño relevante, los beneficiados injustamente no serán los únicos que sufran (o, como ocurre en el caso de la mantención de los diques, puede que sufran un daño mayor que aquel que estaría justificado en razón del grado o nivel de injusticia). La pregunta es, entonces, hasta dónde está justificado el incumplimiento cuando supone estos costos. No tengo una respuesta sistemática a esta pregunta (dudo que la haya). El punto es que la importancia del beneficio que provee una institución, y por ende el costo de perder este beneficio, es un factor que debe considerarse a la hora de determinar si el incumplimiento está justificado, tal y como debe considerarse a la hora de preguntarse si deben los individuos tener un derecho a salirse.

Las cosas son distintas en el caso de aquello que Rawls llama una estructura básica, que incluye los mecanismos para su propia modificación: procedimientos políticos para la creación y reforma de leyes y la presencia de instituciones jurídicas para enfrentarse a las leyes. Para ser justas, este tipo de instituciones deben incluir mecanismos a través de los cuales las demandas de cambio o reforma se puedan hacer efectivas (mecanismos a través de los cuales la "función equilibrante" de un sentido de la justicia compartido pueda realizarse) ${ }^{14}$. Si dichos mecanismos existen, entonces se debilita el caso recién expuesto de cese de cumplimiento justificado.

Pero ocurre que estos mecanismos no existen para el caso del gueto pobre de los Estados Unidos. Como lo enfatiza Shelby, quienes viven allí están tanto política como económicamente aislados. No es sólo un problema de falta de representación adecuada, sino además un estigma que los marca y hace que la sociedad en general esté menos inclinada a tratar seriamente sus reclamos. Su situación yo la llamaría de injusticia persistente: injusticia económica sumada a una ausencia (injusta) de medios políticos efectivos para exigir cambios o reformas. La pregunta aquí es qué tanto están liberados de cumplir con una institución injusta las víctimas de esta injusticia persistente.

Un argumento para permitir incumplimiento en un caso como éste es el de la desobediencia civil como medio de expresión de demandas de

${ }^{14}$ Así Charles Beitz afirma que una de las exigencias de la igualdad política es que los ciudadanos cuenten con medios políticos efectivos para protegerse de la injusticia. Véase su Political Equality, 110-114. 
justicia. Así en el caso de una práctica injusta para evitar los efectos de un químico peligroso, pero por razones diferentes, se justifica también aquí el incumplimiento como medio para protestar por la injusticia persistente porque no existe otra alternativa, ni medios legales para expresar estas demandas por cambio o reforma. El caso clásico de desobediencia civil entiende que aquí está operando una apelación al sentido de justicia de los que están en posiciones de poder, en particular a su reticencia a castigar a los infractores de aquello que reconocen como una ley injusta. Por las razones mencionadas arriba relativas al aislamiento político de los guetos pobres, esta apelación puede resultar menos efectiva en el caso de la injusticia económica que en el caso del desconocimiento de derechos civiles: si la mayoría percibe a los ciudadanos de los guetos como flojos e inmorales, entonces los actos de desobediencia civil en apoyo a una demanda por mayor igualdad de oportunidades pueden no ser efectivos, porque no logran apelar al sentido de justicia de la mayoría.

Esto nos lleva a la pregunta de si aquello que he llamado injusticia persistente anula la obligación de cumplir con las leyes por parte de los ciudadanos desaventajados (que es una cuestión distinta de si el no cumplimiento es un medio efectivo para promover cambios o reformas que tiendan hacia una mayor justicia). La analogía con un sistema de cooperación como el del ejemplo del químico peligroso sugiere que éste podría ser el caso: si una institución es persistentemente injusta, y el no cumplimiento por parte de aquellos que son tratados de modo injusto no supone costos inaceptables, entonces la mayoría no puede reclamar que esos ciudadanos que son víctimas de la injusticia persistente están destruyendo vínculos de reciprocidad al dejar de acatar las leyes. Estos vínculos ya han sido sistemáticamente vulnerados por la mayoría. No obstante, es necesario mirar más de cerca la cuestión de cuáles leyes podrían violarse de modo justificado y por qué.

Aun cuando los residentes de los guetos no tengan ninguna obligación de cumplir con cada ley como tal, seguirán teniendo deberes naturales con otros. Seguiría siendo incorrecto a su respecto provocar un daño, lesión o muerte a otro individuo. Muchas formas de hurto también estarían en esta categoría. Incluso si las instituciones de propiedad son injustas, es incorrecto sustraer el alimento de otros, o medios de subsistencia, como el automóvil que usan para llegar al trabajo.

Pero existen muchas leyes que prohíben otras conductas; tengo en mente leyes que regulan la demarcación de territorios, uso de drogas, el 
ejercicio de prostitución e instituciones económicas y financieras. No resulta implausible, creo, sostener que las víctimas de injusticia extrema estarían justificadas al quebrantar leyes de este tipo (vendiendo drogas, por ejemplo) cuando se hace necesario para subsistir o apoyar a sus familias ${ }^{15}$. No resulta claro que en la violación de este tipo de leyes haya además una violación a deberes de reciprocidad para con el resto de nosotros.

La plausibilidad de esta afirmación (al menos a mí me parece plausible) descansa en varios factores que deben hacerse explícitos. Primero, se apela a la necesidad: al hecho de que estas formas de delitos pueden ser la única vía disponible de supervivencia económica para los residentes del gueto. Este factor está presente también en el ejemplo familiar del padre que sustrae una droga, necesaria para salvar la vida de su hijo, de un farmacéutico que se rehúsa a vendérsela, o se rehúsa a hacerlo a un precio razonable. Segundo, como lo sugiere el concepto "razonable", también está presente la cuestión de si el delito priva a otro de cosas respecto de las cuales tiene una justa titularidad. Algunos de los mencionados son "delitos sin víctima". El carácter injusto del quebrantamiento de aquellas leyes que prohíben esas acciones (y por tanto la permisibilidad de su reforzamiento) disminuye dramáticamente si el proceso político por medio del cual se producen resulta ser seriamente injusto. Incluso cuando el quebrantamiento de las leyes supone un costo para otros, si los beneficios que se pierden son beneficios que se obtienen sólo en virtud de la naturaleza injusta de la práctica, entonces, como afirmé más arriba, parece seguirse que queda excluida para la víctima la posibilidad de reclamo por la pérdida.

Los deberes de justicia, no obstante lo anterior, limitan el no cumplimiento de una manera distinta. El deber natural de promover la existencia de instituciones justas requiere, creo, que las víctimas de la injusticia no actúen de formas que previsiblemente afecten las posibilidades de mejorar instituciones injustas. Entonces, en palabras de Shelby, este deber les exige "no tomar cursos de acción que claramente exacerbarían las cargas de la injusticia que sufren aquellos que están en las circunstancias del gueto o de otros situados en similares condiciones, al menos no cuando estas consecuencias negativas puedan ser evitadas sin demasiado sacrificio personal"16.

Finalmente, más allá de la pregunta por la obediencia al derecho, y la permisibilidad del reforzamiento, existe otro rango de obligaciones que

\footnotetext{
15 Shelby, "Dark Ghetto", 152.

16 Shelby, "Dark Ghetto", 154.
} 
pueden verse afectadas por la injusticia, como es el caso de la obligación que atañe a aquellos — tratados injustamente - de trabajar (o estar dispuestos a trabajar) en los términos dispuestos para ellos. Si no nos deben a nosotros la disposición de cooperar en estos términos, entonces es injusto privarlos de otras formas de beneficio público, tales como la asistencia pública, seguro médico y otros beneficios que favorecen a los pobres, sobre la base de que se rehúsan a hacer su parte.

Volviendo a nuestra propia perspectiva, en vez de la de los desaventajados, podemos arrojar una luz ligeramente distinta sobre la idea de estar atrapados en una institución que trata a otros de modo injusto. Aquí el sentimiento desagradable surge de constatar que está lejos de nuestro poder la posibilidad de convertir nuestras instituciones injustas en instituciones justas. Esto parece ser cierto. Pero si todo lo que he dicho es correcto, entonces los estándares de justicia tienen implicancias en cosas que podemos hacer: por ejemplo, en la posición que hemos de adoptar en cuestiones como políticas de bienestar, legislación de drogas y cuestiones generales de policía y encarcelamiento. Éstas parecen a primera vista materias de política social antes que de justicia fundamental. Pero si lo que he dicho es correcto, entonces una teoría de la justicia tiene cuestiones importantes que decir al respecto.

Para concluir, he estado investigando la relación entre la moral de las instituciones y la moral de la acción individual. En la última parte de este trabajo me he concentrado en la cuestión de si la justicia de una institución es condición necesaria para la existencia de un deber de cumplir con sus mandatos. $\mathrm{Si}$, siguiendo a Rawls, tratamos a las instituciones básicas de una sociedad como "esquemas de cooperación para el beneficio mutuo", y si entendemos el deber de cumplimiento con dichas instituciones como un deber de reciprocidad para con nuestros pares ciudadanos, entonces parece ser que respecto de una estructura básica injusta, al menos persistentemente injusta, los individuos no tienen un deber (al menos no un deber de reciprocidad para con nuestros pares ciudadanos) de cumplimiento de sus leyes. Ésta parece una conclusión demasiado dura. He tratado de mostrar que el asunto es algo más complejo de lo que esta imagen sugiere. He tratado de mostrar algunas de estas complejidades en la relación existente entre conclusiones sobre la justicia - conclusiones o tesis formuladas en la dimensión de la moral de las instituciones - y conclusiones sobre la moral de la acción individual. EP 


\section{BIBLIOGRAFÍA}

Beitz, Charles. Political Equality: An Essay in Democratic Theory. Princeton: Princeton University Press, 1989.

Lessig, Lawrence. Memorandum of October 9, 2009. Consultado en: http://www. ethics.harvard.edu/images/resources/pdfs/v1.0.pdf

Nozick, Robert. Anarchy, State and Utopia. Oxford: Blackwell Publishers, 1999.

Rawls, John. A Theory of Justice, revised edition. Cambridge, Mass: Belknap Bress, 1999.

Scanlon, T. M. What We Owe to Each Other. Cambridge, Mass: Harvard University Press, 1998.

Shelby, Tommy. "Justice, Deviance and the Dark Ghetto". Philosophy \& Public Affairs 35 (2) (2007): 126-160.

Simmons, John. "Justification and Legitimacy". Ethics 109(4) (1999): 739-771.

Williams, Bernard. Ethics and the Limits of Philosophy. London: Fontana, 1985. 